\title{
JOVEM, VELHA JOVITA: UMA HISTÓRIA DE VIDA, UMA BIOGRAFIA
}

mARIA ELIZETE GUIMARÃES CARVALHO

Universidade Federal da Paraíba

- BRUNA KATHERINE GUIMARÃES CARVALHO

Universidade Federal do Rio Grande do Norte

GRINAURA MEDEIROS DE MORAIS

Universidade Federal do Rio Grande do Norte

RESUMO

Compreender o percurso de uma vida, contribuindo com estudos biográficos, é o objetivo do presente artigo. Resultado de uma pesquisa sobre memória feminina, a investigação apresenta problematizações que orientam para vários recomeços. A princípio, abordou histórias de vida de professoras primárias, no decurso do século XX, e, em um momento posterior, histórias de mulheres especiais, que, em suas particularidades, compuseram/compõem o cenário de uma época, a atualidade. Nesse caso em particular, trata-se da história/ biografia de uma prostituta que compôs a moldura de um tempo histórico, de forma singular. Para realizá-la, recorremos a um arcabouço teórico sustentado nas discussões sobre memória, gênero e cultura local. Pesquisamos sobre a vida da personagem até onde as fontes foram confiáveis. Fizemos uma leitura microscópica do seu tempo, do espaço que a abrigava, dos costumes da cidade, dos sujeitos históricos que teciam as redes das tramas cotidianas, de trabalho e diversão, do local. Reconstituímos histórias que estavam soterradas no subsolo do imaginário social. Nesse sentido, compreendemos que histórias de vida como a de Jovita são recriadas constantemente e contribuem para a reescrita da história de um lugar e a moldura de uma época.

Palavras-chave: História de vida. Biografia. Reescrita da história. Memória.

\section{ABSTRACT YOUNG AND OLD JOVITA: A LIFE HISTORY, A BIOGRAPHY}

Comprehending a life way, contributing with biographical resources is the objective of the present article. Result of a research about 
feminine memory, the investigation presents problems that direct on many recommences. At the start, it approached life histories of primary teachers, during the XX century, and at a posterior moment, histories about special women, that, at their particularities, compounded/compound the setting of a season, the actuality. This case, particularly, discusses about the history/biography of a prostitute that has compounded the frame of a historical time in a singular way. To perform it, we applied for a theorist source, based on the discussions about memory, gender and local culture. We researched about the character life until the sources were reliable. We made a microscopic read of her time, the space that accommodates her, the city customs, the historical subjects that weaved the nets of the routine job and fun plot of the local. We reconstituted interred histories in the basement of the social mind. In this way, we comprehended that life histories like Jovita's are recreated every time and contributes to the rewritten of a place history and the frame of a season.

Keywords: Life history. Biography. History rewritten. Memory.

\section{RESUMEN}

\section{JOVEN Y MAYOR JOVITA: UNA HISTORIA DE VIDA, UNA BIOGRAFÍA}

Comprender el trayecto de una vida, contribuyendo con estudios biográficos es el objeto del presente artículo. Resultando de una pesquisa sobre memoria femenina, la investigación presenta problematizaciones que orientan para varios recomienzos. En el principio, abordó historias de vidas de maestros primarios en el decurso del siglo $X X, y$, en un momento posterior, historias de mujeres especiales, que en sus particularidades compusieron/componen el senario de una época, la actualidad. En ese caso in particular, se trata de la historia/biografía de una prostituta que compusiera la moldura de un tiempo histórico de forma singular. Para realizarla recorremos a una fuente teórica sustentada en las discusiones sobre memoria, género y cultura local. Pesquisamos sobre la vida de la personaje hasta las fuentes fueron confiables. Hicimos una lectura microscópica de su tiempo, del espacio que la abrigaba, de las costumbres de la ciudad, de los sujetos históricos que tejían las redes de las tramas cotidianas de trabajo y diversión del local. Reconstituimos historias que estaban aterradas en el subsuelo del imaginario social. En ese sentido, comprendemos que historias de vida como la de Jovita son recriadas constantemente y contribuyen para la reescrita da historia de un lugar y la moldura de una época.

Palabras clave: Historia de vida; Biografía. Reescrita da historia. Memoria. 


\section{Introdução}

Há pelo menos 40 anos, uma pequena cidade do interior vivenciou dentre suas tantas histórias, uma delas, que está guardada nos recônditos da memória até os dias atuais, através da sucessão das gerações. Trata-se dessas memórias vividas e que, com o passar dos anos, se tornam acontecimentos remotos que, de forma indelével, nos acompanham pela vida afora, e se "colam" ao nosso imaginário. São fatos que não são jamais esquecidos, mesmo com a degeneração da memória biológica, que tende a se esmaecer com o passar dos anos, ou, mesmo, como aqueles fatos que não sofrem a ação seletiva da memória social ou entram em negociação para permanecerem vivos. Toda memória é, pois, seletiva. Como explica Pollak (1989, p. 1-2):

Em vários momentos, Maurice Halbwachs insinua não apenas a seletividade de toda memória, mas também um processo de 'negociação' para conciliar memória coletiva e memórias individuais: 'Para que nossa memória se beneficie da dos outros, não basta que eles nos tragam seus testemunhos: é preciso também que ela não tenha deixado de concordar com suas memórias e que haja suficientes pontos de contato entre ela e as outras para que a lembrança que os outros nos trazem possa ser reconstruída sobre uma base comum'.

Nessa perspectiva, trazemos a narrativa de alguns momentos da história de vida de uma senhora cuja identidade civil em notas cartoriais não podemos revelar, por questões éticas referentes à pesquisa, respeitando sua imagem e a de sua família, mas que, entretanto, a trataremos por Dona Jovita, uma prostituta no auge dos seus quarenta anos, não fosse a aparência de pessoa bem mais velha, a contar pela representação de uma senhora sofrida (porém alegre), de uma vida apregoada pelas dificuldades, marcada pela pobreza material, pela discriminação social e pelo preconceito. Estas contradições serão discutidas neste arti- go como ponto chave para uma reflexão mais profunda. Como explicar os opostos de sofrimento e alegria, solicitude e rejeição, religiosidade e deboche, apresentados como comportamentos de uma pessoa?

Considerando a capacidade biográfica de revelar o outro, fazemos de Dona Jovita a "protagonista" de sua história de vida, apoiandonos na abordagem biográfica proposta por Dosse (2009), em que os estudos biográficos permitem revelar o outro, mesmo que esse outro seja um sujeito comum ou anônimo. Nesse sentido, e como nos ensina Loriga (2011, p. 25) sobre a nova biografia, esta é revestida de "acentos anti-heroicos: não tomo nunca o partido dos pretensos heróis, mas vejo sempre o trágico no vencido. A biografia romanceada não afasta apenas os historiadores, mas também os romancistas".

Assim, é a partir dessa perspectiva biográfica que desenhamos nosso encontro com a "protagonista", recolhendo as memórias, os ecos e os sinais de sua trajetória de vida.

É como observa Febvre (apud LE GOFF, 2012, p. 514):

A história faz-se com documentos escritos, sem dúvida. Quando estes existem. Mas pode fazerse, deve fazer-se sem documentos escritos [...]. Com tudo o que a habilidade do historiador the permite utilizar para fabricar o seu mel, na falta das flores habituais. Logo com palavras. Signos. Paisagens e telhas. [...].

Nesse sentido, na ausência desses documentos escritos, a história da personagem foi desenvolvida a partir de todos os sinais encontrados, ou seja, "[...] com palavras. Signos. Paisagens e telhas. [...]" (FEBVRE apud LE GOFF, 2012, p. 514).

Dona Jovita tinha altura mediana, pele branca, rígida, seca e enrugada, rosto arredondado, maçãs do rosto rosadas, a trans- 
bordarem uma oleosidade quase repugnante. $\mathrm{Na}$ boca, um batom de um vermelho sangue a denunciar a sua existência. Olhar firme e persistente. Era vaidosa, usava um vestido reto do tipo "tubinho", um pouco acima do joelho, os dedos ornados de muitos anéis, as pernas tortas a usarem calçados altos ou tênis.

Sua residência fixa era o cabaré, um tipo de moradia das chamadas "raparigas" da época ou "baixo meretrício", 2 palavra de herança francesa do nome do lugar que abrigava as "mulheres da vida". Sabemos pouco sobre a sua genealogia, quiçá decidimos por não aprofundar a pesquisa sobre estes dados junto aos seus familiares, a fim de evitar transtornos, ao "remexermos" uma história que certamente causaria mal-estar e vergonha aos que rejeitavam sua conduta, compartilhando com a sociedade posturas de desprezo e de indiferença a esse ser humano. Com isso, a clandestinidade da memória perpetua-se, aguardando o momento de invadir o espaço público. Nas palavras de Pollak (1989, p. 7):

O problema que se coloca a longo prazo para as memórias clandestinas e inaudiveis é o de sua transmissão intacta até o dia em que elas possam aproveitar uma ocasião para invadir o espaço público e passar do 'não-dito' à contestação e à reivindicação; o problema de toda memória oficial é o de sua credibilidade, de sua aceitação e também de sua organização. Para que emerja nos discursos políticos um fundo comum de referências que possam constituir uma memória nacional, um intenso trabalho de organização é indispensável para superar a simples 'montagem' ideológica, por definição precária e frágil.

Desse modo, e considerando o inaudivel na biografia de Dona Jovita, observemos aspectos

1 Neste contexto, era o lugar onde moravam as chamadas "mulheres da vida" ou "raparigas" do lugar ou as que vinham de outras paragens. Um espaço muito simples, condições precárias, cujo cenário remonta a um grande lajedo e casebres ao redor.

2 O mesmo significado de cabaré. No entanto, o termo é pouco usado pela comunidade em apreço. de sua trajetória de vida, da infância vivida, do cotidiano em que nasceu e se criou. Se houve traumas de infância ou quaisquer outros transtornos psicológicos com a nossa personagem, estes foram levados consigo para o túmulo. Em seu tempo, tudo era absolutamente difícil, impeditivo de confissão. Psicólogos a esta época ainda se constituíam um sonho dos idealistas, principalmente em pequenas cidades interioranas, embora o mundo já tivesse consagrado notoriedade, por exemplo, a Sigmund Freud e seus contemporâneos. Seus segredos de intimidade foram burilados no consciente e no inconsciente de suas paixões, escolhas e decisões. Grosso modo, o que se sabe é que Jovita transgrediu as normas e condutas do seu tempo, ${ }^{3}$ gerou conflitos de família, afrontou as "damas" da época e os homens de "moral" que a conheceram.

Um dia, estas "memórias subterrâneas" (POLLAK, 1992) seriam narradas e publicizadas. De uma forma ou de outra, elas estavam latentes, esperando uma oportunidade para exumarem-se do subsolo que as retinha. Oportunidade esta que nos possibilitou trazer a vida de Dona Jovita para o centro destas páginas, transformando-a em história para o tempo presente, especialmente para os apreciadores e estudiosos de gênero. Adicionemos a esse fato uma mera coincidência: o interesse das autoras por histórias de vida e a dedicação que decidiram aplicar-lhes. Halbwachs (2006, p. 80), nos faz refletir sobre o fato de que:

[...] quando a memória não tem mais por suporte um grupo, o único meio de salvar tais lembranças é fixá-las por escrito em uma narrativa seguida, uma vez que as palavras e os pensamentos morrem, mas os escritos permanecem. Assim, a arte da escrita se apresenta como a possibilidade de garantia de continuidade, de salvação da oralidade.

3 Primeira e segunda metades do século XX, no cenário de uma pequena cidade do interior norte-rio-grandense. 
A esse autor recorremos como inspiração de fonte teórico-historiográfica; neste caso em particular, nos valemos do fato de que a memória se transforma em história, precisamente, quando escrita. E não só por isso. Quando o grupo social ao qual pertence o sujeito está se desfazendo, não existe mais ou não se encontra disposto a narrar sobre os acontecimentos, entende-se que é hora de transformar esta memória em história narrada, escrita, a fim de que a mesma não se perca em algum lugar do tempo subjetivo da sociedade. As narrativas foram coletadas com fundamento na história oral, com entrevistas semiestruturadas de pessoas da comunidade, que participaram da pesquisa com suas memórias e histórias. Anteriormente, foram organizadas algumas questões, considerando alguns relatos sobre a vida de Dona Jovita, que circulam na comunidade.

A História oral é uma metodologia de pesquisa e de constituição de fontes para o estudo da história contemporânea surgida em meados do Século XX, após a invenção do gravador e da fita. Ela consiste na realização de entrevistas gravadas com indivíduos que participaram de, ou testemunharam, acontecimentos e conjunturas do passado e do presente. (ALBERTI, 2004, p. 155)

Halbwachs (2006) juntamente com Pollak (1992), para quem as memórias subterrâneas ${ }^{4}$ são importantes, e Certeau (2002) foram os sustentáculos deste trabalho, escrito a seis mãos, que se encorajaram diante do desafio de relatar fatos que necessariamente precisavam ser contados com cautela, ética, moderação, tendo em vista a intenção de narrar/registrar/ problematizar, sem contudo abrir feridas, quiçá ainda não cicatrizadas, e tampouco macular a imagem da personagem. Argumentando sobre a importância das memórias subterrâneas,

4 As memórias subterrâneas são aquelas que se encontram no seio da família, que realizam um trabalho de subversão, no silêncio e de maneira imperceptível, aflorando em momentos de crise.
Pollak (1992) as entende como parte integrante das culturas minoritárias e dominadas, opondo-se à memória oficial, no caso, à memória nacional.

$\mathrm{Na}$ perspectiva de escrevermos essa história de vida, a pesquisa fundamentou-se nas contribuições da história cultural que propôs a ampliação do conceito de fonte, de sua utilização, assim como considerou novas perspectivas de problematização dos objetos de investigação. Com um outro olhar, essa nova abordagem abre inúmeras possibilidades de investigação para o historiador, como a escuta de um indivíduo, de um grupo ou de uma coletividade, contribuindo para a compreensão de uma época, de um lugar, de um indivíduo em particular, de uma sociedade. Em suas reinterpretações, encontra-se a noção de tempo histórico. É como explica Reis (2000, p. 32): “O presente liga-se ao passado e o passado ao presente de tal forma que o passado se torna presente e o presente imuniza-se contra a sua sorte que é se tornar passado".

Em razão das circunstâncias explicitamente apresentadas e das reservas que sabemos envolver autoria e publicação, este artigo apresenta uma feição literária com o arrolamento de pseudônimos, adereços, evidências, criações, inspirações e conjecturas para formar o substrato e o invólucro de um fato real. Tratase de um diálogo entre história, ${ }^{5}$ memória $^{6}$ e

5 História - é reconstrução sempre problemática e incompleta do que não é mais. Uma representação do passado. Na história, a operação intelectual é laicizante, implica em análise e discurso crítico. Tem vocação universal e prende-se às continuidades temporais, às evoluções e as relações entre as coisas. Classifica, recorta, seleciona, registra. Não pode ser reduzida a uma atividade literária de simples curiosidade, livre e aleatória. Tem como substrato a temporalidade. 0 passado é tornado exclusivamente racional, metamorfoseado em conhecimento.

6 Memória - faz história vivida, movida por inspiração, subjetividade, não apenas a racionalidade; é trazida pelos grupos vivos, aberta à dialética da lembrança e do esquecimento, é um fenômeno atual, afetiva, mágica, subjetiva, seletiva, sempre suspeita para a história. Está aprisionada à linguagem, à palavra. Firma-se em assegurar as permanências, as continuidades, a 
literatura, ${ }^{7}$ um arcabouço teórico recrutado em Jorge Luís Borges. ${ }^{8}$

O imaginário pertence ao campo da representação mas ocupa nele a parte da tradução não reprodutora, não simplesmente transposta em imagem do espírito mas criadora, poética no sentido etimológico da palavra. Para evocar uma catedral imaginária é preciso recorrer à literatura ou à arte: à Notredame de Paris de Victor Hugo, aos quarenta quadros da Cathédrale de Rouen de Claude Monet, à Cathédrale engloutie dos prelúdios de Claude Debussy. Mas o imaginário, embora ocupando apenas uma fração do território da representação, vai mais além dele. A fantasia - no sentido forte da palavra - arrasta o imaginário para lá da representação, que é apenas intelectual. (LE GOFF, 2012, p. 11-12)

Com vistas a oportunizar esse diálogo e compreendermos o imaginário e as representações de um período, ouvimos histórias e memórias de um tempo e lugar, em que estavam manifestas trajetórias de uma vida que todos desejavam esquecer, mas que, perceptivelmente, encontravam-se em transbordamento. Assim, compreender essa história de vida é o propósito desse artigo, percorridas as diversas versões colocadas em estudo.

capacidade de viver o hoje. O tempo costurado é mostrado uno, sem fissuras, sem obstáculos em sua trajetória. Encontra-se em suportes que não os textuais, está nas placas, nas festas populares, nos costumes, nos modos de falar, nos vários lugares de memória.

7 Literatura - alheia às circunstâncias históricas, prende-se ao universo imaginário, despreza a cronologia. Concepção romantizada de leitura prazerosa e sensivel à poesia. Não é depositária da verdade porque estaria negando seu próprio estatuto. Firma-se no primado da estética. Comporta as chaves do passado, presente e futuro, num tempo compactuado, permitindo um tempo uno, imóvel. O tempo pode surgir numa referência familiar. No romance, o tempo não é de linearidade, mas de autonomia entre passado, presente e futuro. A prática literária é a representação do mundo real: trata-se do jogo aleatório que ficcional a realidade e a apresenta metamorfoseada, da vontade de raspar o limite do real - sem o atingir, de representá-lo, perturbá-lo, questioná-lo. Proximidade possivel do real.

8 Do livro: Uma memória do mundo: ficção, memória e história em Jorge Luís Borges (PINTO, 1998). Borges foi um escritor argentino nascido no final do século XIX, destacando-se sua obra literária no decorrer do século XX.

\section{Jovem, velha Jovita: vivenciando o preconceito e a discriminação}

Tudo aconteceu em uma pequena cidade do interior do Rio Grande do Norte, há aproximadamente 350 quilômetros da capital do Estado, cujo nome será omitido nestas páginas, para evitar elucidações comprometedoras.

A cidade, que na década de 1970 tinha por volta de 3000 habitantes, era pacata, de pouquíssima movimentação comercial e de uma economia baseada na agricultura, na criação de bovinos, suínos e caprinos, além da pesca. 0 açude que se lhe avizinha era o ancoradouro e o sustentáculo de vida da maioria da população, bem como o leito do rio que, ao longo de suas margens, garantia o sustento de muitas famílias. Havia também os caçadores, os marceneiros, os barbeiros e os trabalhadores das minas, que garimpavam sonhos de encontrar o minério scheelita. Trata-se do lugar em que o particular e o universal se encontram e onde os temas da identidade e da memória se cruzam. Tal é o local da pesquisa. Na compreensão de Certeau (2002, p. 66):

Toda pesquisa historiográfica se articula com um lugar de produção sócio-econômico, político e cultural. Implica um meio de elaboração que circunscrito por determinações próprias: como profissão liberal, um posto de observação ou de ensino, uma categoria de letrados, etc.

Nesse sentido, e a partir da articulação com seu espaço de produção, a pesquisa historiográfica discutida nesse trabalho traz as marcas desse espaço, compreendendo-se que a história tem como um de seus propósitos dialogar com a experiência do outro, com as muitas histórias produzidas, o que aponta para a necessidade de buscarmos as várias versões de um mesmo acontecimento, para que nada se perca ou seja esquecido pelas gerações. As narrativas sobre Dona Jovita já se transformaram em memória coletiva, em patrimônio cul- 
tural daquela pequena cidade. Vejamos como Le Goff (2012, p. 541) compreende a evolução da memória coletiva:

A memória coletiva valoriza-se, institui-se em patrimônio cultural. 0 novo documento é armazenado e manejado no banco de dados. Ele exige uma nova erudição que balbucia ainda e que deve responder simultaneamente às exigências do computador e à crítica da sua sempre crescente influência sobre a memória coletiva.

E é ainda a memória coletiva que afirma a presença das diferenças sociais naquela comunidade, com um número de proprietários rurais e de pequenos comerciantes considerados os ricos da cidade e a quem se devotava respeito e obediência. Eram eles que detinham o poder sobre os mais pobres, cujas feiras eram feitas nas suas bodegas, ${ }^{9}$ e as vendas afiançadas pela palavra, contas que eram anotadas em cadernetas e em muitos casos pagas no final do ano, com a apuração da venda do algodão. Os filhos de tais comerciantes destacavam-se dos outros jovens da cidade, por terem a oportunidade de estudo $^{10}$ mais ampliada e, pelo poder de aquisição de roupas e, especialmente, calçados. Os demais jovens constituíam a maioria, filhos de agricultores e professores públicos, como se costumava denominar os funcionários da rede pública de ensino.

Vivia-se em "convivência pacífica", não obstante as diferenças, camufladas por desigualdades sociais nem sempre visíveis. Todos participavam da única praça, a única igreja católica apostólica romana, o mesmo clube, as mesmas festas, alimentados pelo sonho ingênuo de um país que marchava rumo ao progresso, pelo menos nos discursos ideologizantes da ditadura (1964-1985). As festas do padroeiro

9 Locais de venda de cereais e mantimentos, geralmente bem simples, onde se usava a balança e o peso, bem como embalagens de papel de embrulho.

10 As oportunidades de estudo para os filhos de tais comerciantes davam-se com a formação em cursos superiores, realizados nas universidades das capitais, principalmente os cursos de Medicina e de Direito. eram compartilhadas pelo espírito animoso dos seus habitantes que, afortunados ou não, se desdobravam em serviços e vaidades mostrando o que de melhor podiam apresentar.

O calçamento das ruas e a energia elétrica foram serviços que somente vieram a se consolidar no final da década de 1960. Tudo girava em torno do mercado, da igreja, da praça e da prefeitura, espaços estes ladeados por duas ruas competitivas e adversárias, denominadas de rua do norte e rua do sul, separadas pela avenida principal, onde, de uma das suas pontas avistava-se o cabaré onde morava Dona Jovita e suas companheiras, um lugarejo com um amontoado de casas bem rudes, um grande lajedo, onde se viviam os grandes momentos, para muitos, festivos, e, para outros, pecaminosos, amaldiçoados e malditos. Assim como Dona Jovita, havia outras mulheres no cabaré, suas companheiras de vida e de histórias, e o lugar pleno de significados, produtor de sentidos, da constituição de memórias tramadas entre homens e mulheres. O lugar de implicâncias da sociedade.

A cidade também criava e mantinha seus "loucos" (homens e mulheres), que viviam à margem da sociedade, completamente merguIhados no mundo "anormal". Citaremos alguns pseudônimos que também marcaram a vida da cidade, com suas especificidades idiossincráticas: Bambão, Inácio Malaquias, Manoel Feijão, Joaquim Doido, Cristiana Aleijada, a véia do sebo, a feiticeira Florinata, Balbina, Hélio e tantos outros, que, por suas diferenças pessoais, foram vítimas do modelo social que se tomava por correto, perfeito e normal, regulador da sociedade em foco. Pessoas que, no palco de suas existências, tiveram suas vidas atravessadas pelas vozes da rejeição. Todos trabalhadores e trabalhadoras anônimos, sujeitos da história do lugar, personagens indescritiveis em importância nas avenidas da memória da cidade. 
A respeito dos sujeitos anônimos, Medeiros Filho (2010, p. 21-22) em seu livro Cumpli-cidade relata:

Junto aos já decantados heróis tradicionais, aqueles que, mesmo totalmente indispensáveis à história, nem sempre receberam as láureas do reconhecimento público. Da obscuridade e do esquecimento, surgem reluzindo nos afazeres cotidianos do trabalho, proporcionando cheiro, cor e sabor à intrincada dinâmica da sociedade. São estrelas recortadas do labor diário, das prementes lidas da sobrevivência. Enquanto se esforçam por viver, forçam a permanência do lugar. Emergem do limbo amnésico as lindíssimas figuras da vida sertaneja e despedem o véu de sombra que o tempo e o preconceito the reservavam. Esses anônimos, aparecendo às centenas, têm mãos e pés de texturas calosas, almas tão fortes quanto os mourões dos currais e vêm inscrever-se no rol da história, ladeados pelos nomes já consagrados pela tradição.

Isto mesmo! Difícil não dizer para as novas gerações da importância dessas pessoas no cenário histórico e na construção da cidade. Impossivel não lhes reservar um lugar na história, independentemente das figuras tradicionais, colocando-as lado a lado na linha de tempo dos acontecimentos do lugar. 0 autor faz uma homenagem a vários personagens anônimos da história, dentre eles: ao tapuia, ao vaqueiro, ao agricultor, à dona de casa, ao pescador, à parteira, ao professor, ao artista, ao marceneiro, à prostituta. Para esta, dedicalhe o poema das páginas 92-93.

\section{A PROSTITUTA \\ Penso em carregar teu algodão quero conduzir teu algo vão deixa eu transportar teu algo ou não deixas?}

Amor comparado a algodão ouro branco exposto, algo à mão eve como pluma, algo tão caro
Sonho possuir teu algodão tento adquirir teu algo, em vão posso possuir teu algo ou não posso?

Vendes o teu corpo, algo cão para mastigares algum pão mas teu beijo, o amor, teu algo são negas

Quando eu conseguir teu algodão não serás daquelas que algo dão fácil. Guardarei teu algodão dócil. (MEDEIROS FILHO, 2010, p. 92-93)

A historiografia oficial não tinha lugar para estes ilustres anônimos. Suas histórias bem como a de Dona Jovita e de suas companheiras só nos são possíveis porque as pesquisas tomaram um outro rumo, direcionaram-se para as abordagens qualitativas, para escritos e testemunhos deixados por sujeitos antes impedidos de entrar na história. Por causa do alargamento das fontes, ${ }^{11}$ das técnicas, da transformação e da ampliação do próprio conceito de história. Para Almeida (1998, p. 48):

Buscam recuperar uma história desenrolada no espaço doméstico, nas relações de poder no âmbito privado, na vida de significâncias cotidianas e, dessa forma, descortinar o sujeito histórico encoberto pelo passado. Essas investigações possibilitaram entrever a emergência de novos paradigmas de análise e as escolhas profissionais e pessoais das mulheres deixaram de ser enfocadas apenas como decorrentes da situação concreta das esferas produtivas e passaram a ser vistas também como opções determinadas pela vida em si, pelos sentimentos que ela libera e pelas relações subjetivas que, além das objetivas, perpassam o cotidiano dos seres humanos e nele imprimem sua marca.

Nesse mesmo sentido, Cadiou et al (2007, p. 204), ao referirem-se ao projeto biográfico,

11 Esta possibilidade dá-se a partir do movimento de renovação da historiografia, iniciado em 1929, na França, com a Nova História, e tendo alcançado os dias atuais, como um movimento crescente e promissor de uma história transformada em suas concepções. 
explicam que tal projeto se utiliza de fontes diversificadas: "patrimônio público (relatórios policiais), novas fontes escritas (atos notariais, crônicas judiciárias), materiais (arqueologia) e orais. As pesquisas são igualmente múltiplas: podemos inserir indivíduos "sem história" em seu meio".

Surge então o interesse de escrever sobre Dona Jovita, uma personagem "sem história", uma trajetória de vida "sem coerência". Suas lutas diárias por alimentação, pela bebida alcoólica, pelo serviço prestado no recebimento aos clientes, sua forma de se manter viva no trabalho, na labuta pelas ruas da cidade. Dona Jovita saía de porta em porta, pedindo ajuda, às vezes encontrava galinhas mortas pelos "monturos", apanhava-as e continuava em seu trabalho de pedinte. Tudo era aproveitado por ela, sem que the fosse arrancado o seu jeito de ser, de se vestir, de cantar, de murmurar uma música que, aos outros, poderia parecer um desabafo, especialmente por quem a desprezava e cujas estrofes ainda soam aos ouvidos de uma geração: "Para que tanto orgulho, se somos iguais, para que tanto orgulho, se somos iguais. Para que separação, se somos irmãos".

Na rotina da vida e do trabalho, acostumara-se à bebida alcoólica; todos os dias, tomava as suas chamadas de cana,12 antes de sair para pedir. Por vezes a víamos caída pela rua. Certa vez, o fato aconteceu na cozinha de uma casa a que ela teve acesso. Por várias vezes, foi presa pela polícia, por causa da bebida. Nos dias de feira, era comum vê-la embriagada no mercado público e, ao final da feira, ir para a delegacia. Que fazia Dona Jovita, diferentemente de outras pessoas, incorrendo no mesmo erro, no mesmo comportamento? Atentado ao pudor? Certamente que atitudes transgressoras deviam afrontar a sociedade, que, na contramão da história, também afrontava Dona Jovi-

12 Termo popular para uma dose de aguardente. ta, quando guardava, na moral social, muitos casos de transgressão de homens e mulheres, que não eram revelados. Sociedade esta que também the faltava com o respeito, mesmo nas formas mais elementares de tratamento humano. Dizia-se que, na ausência de cama, dormia sobre um pneu de caminhão. Seriam os palavrões? Não se tem notícia de que os pronunciasse.

Por vezes, abordava as pessoas fazendo uma espécie de bênção, que se confundia com maledicência e santidade, cura e medo do satanás. Uma mistura de reza e de embriaguez parecia the dar o poder de fazer as pessoas acreditarem no que fazia. Dona Jovita sabia que o poder da mente podia the render algum respeito e, para isso, utilizava-se dos recursos de que dispunha: a mente embriagada e carregada de fagulhas de fé adquiridas em algum lugar das crendices populares ou dos fragmentos religiosos oriundos da igreja católica, para onde ela nunca ia, talvez por saber do lugar que a sociedade the reservara. Uma prostituta na igreja era caso impeditivo no seu tempo. Desse modo, a personagem procurava resistir à situação de dominação cotidiana, utilizandose de pequenas "manobras", táticas de poder que confundiam a sociedade que a desprezava. Nas palavras de Certeau (2002, p. 104), a tática constitui-se de "gestos hábeis do fraco, na ordem estabelecida pelo forte, arte de dar golpes no campo do outro, astúcia de caçadores, mobilidade nas manobras, operações polimórficas, achados alegres, poéticos e bélicos". E Dona Jovita apropriava-se dessas táticas, para melhor viver ou subsistir naquela sociedade.

Estudos que abordam o temário feminino viriam adentrar as academias, em meados da década de 1970, na mesma década em que se desenrola a história da nossa personagem, estando tais temas explicitamente associados aos conceitos de raça e de classe social. Desta forma, foi introduzido o conceito de gênero 
como categoria científica explicativa das relações sociais entre os sexos, embora este termo tenha permanecido por muito tempo como sendo atribuído às mulheres. Atualmente, é atribuído aos dois sexos e é entendido como uma construção social, histórica e cultural, elaborada sobre as diferenças sexuais. Tomado e entendido como construção, tem-se uma mais proficua amplitude dos estudos, das interpretações que se fazem dos dados das pesquisas ao alargamento e visibilidade do olhar que se lança sobre o objeto.

0 conceito de gênero não se restringe mais unicamente a um sexo, ampliou-se para as relações socialmente construídas entre eles. Relações estas que remetem às relações de poder e que revelam os conflitos e as contradições que marcam a sociedade. Almeida (1998, p. 40-41) adianta que:

[...] as configurações de poder entre os gêneros, da mesma forma que os significados, as normatizações valorativas, as práticas e os símbolos, variam de acordo com as culturas, a religião, a economia, as classes sociais, as raças e os momentos históricos, formando redes de significações que se edificam e se relacionam integradamente e atuando em todos os âmbitos da vida cotidiana.

Narrar sobre um personagem é falar do seu tempo. Quando escolhemos escrever uma história de vida, é da moldura do tempo que nos apropriamos, que tomamos para a investigação e para a análise da pesquisa. No caso da personagem em estudo e dos seus contemporâneos, foram sujeitos que viveram em um tempo profundamente marcado pelas desigualdades sociais, literalmente explícitas em todos os níveis; em uma sociedade controlada por um sistema político repressor, que vivenciou os piores anos da ditadura, em uma cidade de interior desprovida das condições de respeito à dignidade humana. Todos os sujeitos históricos, independentemente de ida- de, sexo, religião, cor e classe social, tiveram suas vidas atravessadas por este momento de intensa pobreza material e intelectual, pelo cerceamento das ideias e ao exercício livre da cidadania.

Dona Jovita, neste contexto, estaria enquadrada nas categorias de mulher, pobre e prostituta. A inferioridade biológica e social da mulher, que ainda se fazia sentir na época, apoderara-se do pensamento vigente naquela pequena cidade interiorana. Porém, tal estatuto de fragilidade era contestado/negado pela personagem, que apresentava atitudes de coragem, de subversão, de transgressão da ordem, de superação dos insultos e das humilhações dos homens, dos deboches ouvidos nas ruas, das acusações e indiferenças das famílias, da frieza social à sua condição humana. Desse modo, Dona Jovita resistia a essa conclamada inferioridade biológica e social, reagindo em sua forma de ser e estar no mundo.

Contrariamente a esta “índole transgressora", que incomodava a sociedade, narravase que Jovita tinha bons sentimentos, não se dava à violência, não fazia "arruaças" pelas ruas, não desrespeitava os outros. Teria depurado as humilhações sofridas em prol da purificação do espírito? Que forças subliminares a faziam ainda serena? Teria sido para ela a música de Chico Buarque de Holanda? Quantas Geni, quantas Jovitas, quantas pedras, caminhos esticados de uma jornada tão dura. Havia fugas para suportar a insuportável realidade? Que prazer existia em ser pedinte, insultada, espancada, ultrajada na essência do ser? As orgias ajudavam a suportar a realidade? Não seriam elas as causas de toda esta discriminação? O filósofo Edgar Morin (2001, p. 23) refere-se à suportável realidade, destacando a crueldade da realidade e da condição humana. Para ele:

a incerteza face ao destino e a inevitabilidade da morte fazem o sapiens demens criar estratégias 
para suportar a crueldade da realidade. O sofrimento, a alegria, a tristeza, o prazer, a felicidade, a infelicidade etc., revelam a excitabilidade, a emotividade, a irritabilidade que o torna vulnerável a todos os golpes do destino e engendram a condição humana. O homem constrói formas de diálogos para suportar a realidade: o compromisso neurótico, a estética, a cooperação e o controle são espécies de tentativas para ordenar a realidade e confrontar a crueldade do mundo. É impossivel escapar à dialógica sapiens/ demens a partir da qual se tece a condição humana. Torna-se urgente assumir o jogo dialógico entre racionalidade e afetividade, prosa e poesia, enquanto nosso destino.

Cada um, a seu tempo, organiza as formas de escapar à dureza da vida. Em nosso caso, e considerando os equipamentos materiais e imateriais de que dispomos, somos levados a buscar algo que nos proporcione distração, o sair do lugar comum. Atualmente, mais do que nunca, somos vítimas de uma sociedade que tem pressa, que procura dar outro ritmo ao tempo, que apressa as águas do rio, na linguagem do poeta. Trata-se da síndrome do pensamento acelerado, tão propalado pelos profissionais da área humanística como o mal causador dos problemas que atacam a mente humana e que conduzem as pessoas a comportamentos sociais “indesejáveis".

A época em que viveu Dona Jovita também apresenta seus grandes problemas. Para compreendê-los ou querermos sentir um tempo vivido pelos outros, teremos que abolir ou esquecer grande parte dos equipamentos e dos bens de que dispomos hoje, conseguidos, quiçá, às custas das gerações aproximadamente avizinhadas a nossa. Vivendo em uma sociedade com uma dinâmica de vida precária e modesta, carregando o fardo da discriminação e da intolerância, das censuras da tradição, este era o estilo de vida que a personagem escolheu para viver.

Observando a possibilidade de articulação entre a personagem e seu tempo, sua vida e seu contexto, apresentamos interpretações sobre o fazer cotidiano de Dona Jovita, na batalha pela subsistência, não acalentando a ilusão de estarmos fazendo "falar a realidade", mas deixando a "porta entreaberta para revisitações". É como explica Dosse (2009 p. 410):

Em sua era hermenêutica o biógrafo já não tem a ilusão de fazer falar a realidade e de saturar com ela o sentido. Ele sabe que o enigma biográfico sobrevive à escrita biográfica. A porta permanece escancarada para sempre, oferecida a todos em revisitações sempre possiveis das efrações individuais e de seus traços no tempo.

Dona Jovita não envelheceu aos nossos olhos! Sua estrutura física definhou, seu corpo já não mais ganhava as distâncias que percorria ao longo das ruas, era o que se sabia nas notícias que se tinha através dos amigos e da família. Muitos jovens da geração de 1970 seguiram outros rumos, para além da cidade. Soube-se que ela foi resgatada por uma filha que morava ao longe. E lá se foi a nossa personagem que queria viver e amar, a dar ao mundo o testemunho da vida tal qual ela é, pelo menos da sua própria vida.

\section{Considerações Finais}

Não é tarefa fácil compreender uma vida pelas histórias narradas, pelo testemunho de memórias voluntárias ou involuntárias, que muitas vezes se aproximam da ficção ou da mitologia, o que nos passa a impressão de que estamos no limiar entre história e literatura, já que uma imagem é criada, recriada, destruída, em suas permanências e rupturas. Tal condição não implica em desconfiança, mas em respeito pelas diversas versões e pela subjetividade dos depoentes, pois, se escutássemos narrativas de vida univocas, caracterizadas pela "predestinação e coerência das personalidades" (CADIOU et al, 2007, p. 205), estaríamos distanciadas do projeto biográfico atual e das demandas históricas do nosso tempo. 
Nessa perspectiva, optamos pela escritura da história de vida de uma personagem "anônima", "sem história", mas que marcou o cenário de uma cidade, encontrando-se sua memória em transbordamento, embora voluntariamente a queiram jogar no espaço do esquecimento.

Assim, Dona Jovita resiste na memória da cidade, contribuindo para a moldura de um cenário e de um tempo. Sua resistência à vida está guardada tanto nas lembranças de gerações mais antigas, como nas lembranças dos mais jovens, que, "por tabela" (POLLAK, 1992), relembram histórias, recriam imagens e acontecimentos, enfim, reescrevem a história.

\section{Referências}

ALBERTI, Verena. Ouvir contar: textos em história oral. Rio de Janeiro: FGV, 2004.

ALMEIDA, Jane Soares de. Mulher e educação: a paixão pelo possível. São Paulo: Fundação Editora da UNESP, 1998.

CADIOU, François et al. Como se faz a história: historiografia, método e pesquisa. Tradução de Giselle Unti. Petrópolis, RJ: Vozes, 2007.

CERTEAU. Michel de. A escrita da história. Tradução de Maria de Lourdes Menezes. Rio de Janeiro: Forense Universitária, 2002.

DOSSE, François. 0 desafio biográfico: escrever uma vida. Tradução de Gilson César Cardoso de Souza. São Paulo: Edusp, 2009.

HALBWACHS, Maurice. Memória coletiva. Tradução de Beatriz Sidou. São Paulo: Centauro, 2006.

LE GOFF, Jacques. História e memória. Tradução de Bernardo Leitão et al. 6. ed. Campinas, SP: Editora da UNICAMP, 2012.

0 imaginário medieval. 3. ed. Lisboa: Editorial Estampa, 1994. (Coleção Nova História, 3).

LORIGA, Sabina. 0 pequeno x: da biografia à história. Tradução de Fernando Scheibe. Belo Horizonte: Autêntica, 2011.

MEDEIROS FILHO, João Quintino de. CUMPLI-CIDADE: poemas para o meu lugar. Natal: Sebo Vermelho, 2010.

MORIN, E. A suportável realidade. CRONOS, Natal, v. 2, p. 23-30, jul./dez. 2001.

PINTO, Júlio Pimentel. Uma memória do mundo: ficção, memória e história em Jorge Luís Borges. Prefácio de Maria Ângela Lígia Coelho Prado. São Paulo: Estação Liberdade; FAPESP, 1998.

POLLAK, Michel. Memória, esquecimento, silêncio. Estudos Históricos, Rio de Janeiro, v. 2, n. 3, p. 3-15, 1989.

Memória e identidade social. Estudos Históricos, Rio de Janeiro, v. 5, n. 10, p. 200-212, 1992.

REIS, José Carlos. Os Annales: a renovação teóricometodológica e 'utópica' da história pela reconstrução do tempo histórico. In: SEMINÁRIO NACIONAL DE ESTUDOS E PESQUISAS “HISTÓRIA, SOCIEDADE E EDUCAÇÃO NO BRASIL", HISTEDBR, 4., 1997, Campinas, SP. Anais... Campinas: UNICAMP, 1997. p. 54-73.

Recebido em: 01.09.2018 Aprovado em: 22.01.2019

Maria Elizete Guimarães Carvalho é Doutora em Educação pela Universidade Federal do Rio Grande do Norte/UFRN. Pós-Doutora em Política Educativa pela Universidade do Minho/UMINHO/PT. Professora Associada da Universidade Federal da Paraíba/UFPB. Departamento de Fundamentação da Educação, Centro de Educação. Credenciada aos Programas de Pós-Graduação em Educação/PPGE/UFPB e em Direitos Humanos/PPGDH/UFPB. Pesquisadora do Grupo de Estudos e Pesquisas História da Educação Brasileira, GT - PB. e-mail: mecarvalho23@yahoo.com.br 
Bruna Katherine Guimarães Carvalho é Doutoranda em Ciências Odontológicas pelo Programa de Pós-Graduação em Odontologia - PPGCO, da Universidade Federal do Rio Grande do Norte - UFRN. Mestrado em Odontologia pelo Programa de Pós-Graduação em Odontologia - PPGO, da Universidade Federal da Paraíba - UFPB. Pós-graduação em Reabilitação Oral/COESP/João Pessoa/PB. Cirurgiã-dentista/UFRN. 2o TEN. ODT do Exército Brasileiro. 40o Batalhão de Infantaria - Crateús/CE. Voluntária do Projeto “Educação em Direitos Humanos: Construindo Sujeitos de Direito no Curso de Pedagogia/CE/UFPB", PROLICEN/UFPB. Pesquisadora do Grupo de Estudos e Pesquisas Memória, História e Educação/ UFPB. e-mail: brunaguimaraess@icloud.com

Rua da Saudade, 1035, Lagoa Nova, Res. Palladine, Ap. 502, Bairro Lagoa Nova, Natal, RN. CEP: 59.056-125. Cel. (84) 988084727

Grinaura Medeiros de Morais é Pós-Doutora em Educação em Direitos Humanos pelo Programa de Pós-Graduação em Direitos Humanos, Cidadania e Políticas Públicas - PPGDH - da Universidade Federal da Paraíba. Doutorado em Educação pela Universidade Federal do Rio Grande do Norte. Professora Associada da Universidade Federal do Rio Grande do Norte. Departamento de Educação. Centro de Ensino Superior do Seridó - CERES. Rua Manoel Lopes Filho, 138, Valfredo Galvão, Caicó, RN. CEP: 59.380-000. Pesquisadora do Grupo de Estudos e Pesquisas Memória, História e Educação. e-mail: grinauraufrn@yahoo.com.br

Rua Generina Vale,1210, Centro, Caicó/RN. CEP: 59.300-000. Fone: (84) 99193-4049. 